
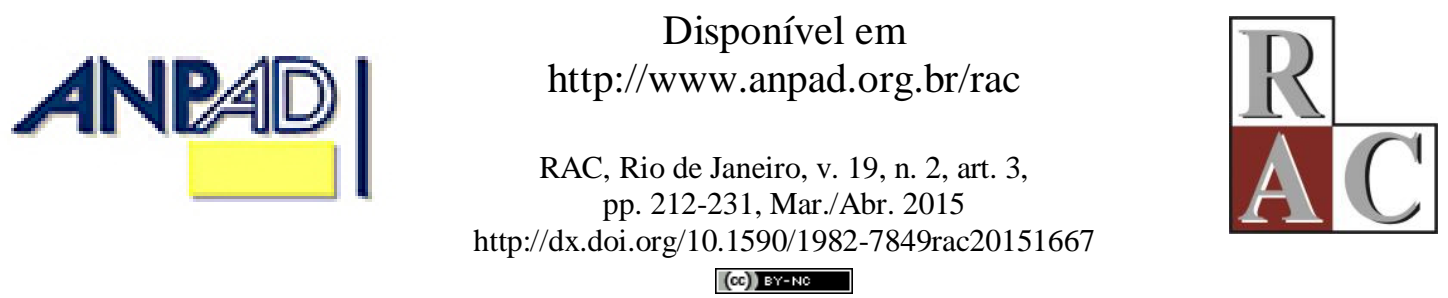

\title{
Governança e Estratégia de Cursos de Graduação em Administração na Perspectiva da Teoria Ator-Rede
}

Governance and Strategy of Undergraduate Business Programs in Light of the ActorNetwork Theory

Ludmilla Meyer Montenegro Universidade Federal de Sergipe - UFS

Sergio Bulgacov Fundação Getúlio Vargas - FGV 


\title{
Resumo
}

Este trabalho, procurando uma maior compreensão do modo de fazer estratégias nas organizações e da constituição das relações formadas entre os atores e as redes de governança, contribui para as teorias Redes de Governança, Estratégia como Prática Social, Resultados Estratégicos e Teoria Ator-Rede, por meio do objetivo: delinear como a articulação do strategizing, como o processo de translação, com a teoria das redes de governança, configuram a governança e os resultados estratégicos de cursos de graduação em Administração de Instituições de Ensino Superior (IES) particulares de Curitiba (Paraná, Brasil). Realizou-se um estudo comparativo de cinco casos por meio de vinte e nove entrevistas semiestruturadas e em profundidade, além de observações não participantes e levantamento de dados de documentos. A análise dos dados foi feita em duas fases: (a) Análise de Narrativas; e (b) Análise Qualitativa Comparativa (Qualitative Comparative Analysis [QCA]). Os resultados mostraram que o processo de strategizing e o entrelaçamento de atores humanos e não humanos são essenciais para a compreensão da governança e dos resultados estratégicos das instituições estudadas. Acredita-se que a articulação teórica proposta no trabalho e os achados da pesquisa empírica formam um corpo de conhecimento consistente e elucidam questões atuais relevantes para compreender nuances relativas às redes de governança, à estratégia como prática social, ao fazer estratégia (e seus resultados) e às questões sociomateriais (atores humanos e não humanos).

Palavras-chave: fazer estratégia; resultados estratégicos; governança; Teoria Ator-Rede; educação.

\begin{abstract}
In order to obtain a more accurate comprehension of organizations' strategizing and of the relations formed by actors and governance networks, this article intended to contribute to the theories used-Governance Networks, Strategy as a Social Practice, Strategic Outcomes and Actor-Network Theory - by delineating how the articulation of strategizing, as a process of translation, with governance network theory configures the governance and strategic outcomes of Business programs in private Higher Education Institutions in Curitiba (Parana, Brazil). The chosen research method was a comparative case study, by which five cases were studied and twenty-nine in-depth semistructured interviews were held, besides non-participant observations and document analysis. Data analysis was developed through (a) Narrative Analysis and (b) Qualitative Comparative Analysis (Análise Qualitativa Comparativa [QCA]). The results showed that the strategizing process and the intertwining between human and nonhuman actors are essential to the comprehension of governance and strategic outcomes of the studied institutions. It is believed that the theoretical articulation undertaken in this paper and the empirical research findings form a consistent body of knowledge and elucidate current and relevant questions to understand nuances related to governance networks, strategy as practice, strategizing (and its outcomes) and sociomaterial issues (human and nonhuman actors).
\end{abstract}

Key words: strategizing; strategic outcomes; governance; Actor-Network Theory; education. 


\section{Introdução}

Neste trabalho, entende-se que as relações formadas entre os atores envolvidos na governança de IES e seus efeitos sobre os seus resultados estratégicos através da análise da formação e da dissolução das redes de governança são aspectos importantes para a compreensão das organizações pesquisadas.

Por sua relevância teórica, tem-se como perspectiva de análise as abordagens da governança, da estratégia enquanto prática social, dos resultados estratégicos e dos atores humanos e não humanos. Com base na Teoria Ator-Rede, que permite observar as ações e as relações dos atores humanos e não humanos, busca-se compreender como esses constituem as práticas do dia a dia das redes de governança, e como estas influenciam os resultados estratégicos de cinco cursos de graduação em Administração, entendendo que o processo de strategizing (fazer estratégia) se configura como translação, que em suas associações permite caracterizar as redes de governança. As redes de governança, por sua vez, compostas por múltiplos atores, produzem uma ordem parcialmente estabilizada na contínua construção de cadeias de mediação do fazer estratégia.

Connolly e James (2011) enfatizam que estão sendo publicados trabalhos relevantes sobre governança, mas trabalhos que tratam de governança e desempenho ainda são incipientes. Esses autores recomendam a importância em se desenvolver mais estudos com a integração dessas teorias.

Nesse sentido, este trabalho também contribui ao ampliar, por meio da investigação empírica, o escopo analítico da teoria das redes de governança, por não ser este suficientemente robusto para explicar a realidade educacional, uma vez que a dita teoria não considera o social na sua forma em plena constituição. Principalmente, por não prever, no seu escopo de análise, as questões humana e material conjuntamente. A Teoria Ator-Rede é utilizada neste trabalho com o intuito de suprir essa lacuna teórica.

Com base nessas questões e nas condições empíricas, o objetivo geral desta pesquisa busca delinear como a articulação do strategizing, como processo de translação, com a teoria das redes de governança, configura a governança e os resultados estratégicos de cursos de graduação em Administração de IES particulares de Curitiba.

O presente estudo foi estruturado da seguinte forma: inicialmente, apresenta-se a síntese teórica do estudo. Em seguida, é delineada a metodologia do trabalho. Na sessão seguinte, apresenta-se a análise dos dados, dividida em duas fases, a Análise de Narrativas e a Análise Qualitativa Comparativa (Qualitative Comparative Analysis [QCA]). Na sequência, são apresentadas as considerações finais. Por fim, elencam-se as referências.

\section{Síntese teórica de referência}

Nesta pesquisa, optou-se por desenvolver uma articulação teórica entre as perspectivas das Redes de Governança, da Estratégia como Prática Social e da Teoria Ator-Rede, uma vez que se percebeu uma possibilidade de avanço teórico, de construção de conhecimento, no que se refere às possibilidades de conversação entre essas abordagens, principalmente com o interesse em explorar o entendimento não apenas dos atores humanos, mas também dos atores não humanos. Assim, a proposta dessa articulação teórica é revelar a atuação desses atores não humanos que a priori não eram contemplados na teoria das redes de governança.

\section{Teoria Ator-Rede e redes de governança}

A noção de redes de governança (Kjaer, 2004; Rhodes, 1997, 2007) propõe-se a compreender as nuances da governança de acordo com os movimentos, interações e mudanças que ali ocorrem, pois se acredita que essa seja uma forma mais coerente de se estudar seus mecanismos, diferentemente de noções, tais como as lógicas hierárquica e de mercado. 
Para Latour (2005), os atores não humanos são essenciais para desvelar o social. Nesse caso, o social é composto por atores humanos e não humanos, e não há primazia de um sobre o outro. Ambos compõem entidades que estão em constante movimento, formando redes heterogêneas e deixando trilhas a serem investigadas. Segundo o autor, o princípio é: olhe para os não humanos quando a emergência de uma característica social for inexplicável; olhe para o estado das relações sociais quando um novo e inexplicável tipo de objeto entrar no coletivo (Latour, 1994a).

Para Latour (2005), se um pesquisador utiliza a Teoria Ator-Rede, ele deve seguir os próprios atores e tentar alcançar suas inovações intensas para aprender com eles o que a existência coletiva tem se tornado em suas mãos, quais métodos eles têm elaborado para fazer com que essa existência coletiva se encaixe, quais explicações poderiam melhor definir as novas associações que eles têm sido forçados a estabelecer.

Entende-se, principalmente no âmbito das IES, enquanto contexto deste trabalho, que questões relevantes para o entendimento dessa realidade organizacional não sejam devidamente explicadas, e que isso gere desentendimentos e ambiguidades para o campo. Acredita-se que, ao se investigarem muitas dessas questões que ainda não foram reveladas, seja porque não se deu a devida atenção a elas, seja simplesmente porque elas são tidas como dadas (taken for granted) e, por isso, não se percebeu a necessidade de investigá-las, será possível compreender melhor os mecanismos e as redes de governança de organizações educacionais e seus resultados estratégicos (Bulgacov, Souza, Prohmann, Coser, \& Baraniuk, 2007; Matitz, 2009).

Pode-se afirmar que tanto a teoria das redes de governança quanto a Teoria Ator-Rede são permeadas por fatores que têm remetido à instabilidade social pela complexidade das organizações educacionais, uma vez que há uma série de atores não humanos como normas, leis e instrumentos que estão sempre em meio a processos de mudança. Destaca-se que a noção de redes de governança remete à realidade atual em que questões governamentais são levadas em consideração, envolvem mecanismos formais e também mecanismos informais que estão em constante formação e dissolução.

Todavia, convém ressaltar que a Teoria Ator-Rede é alvo de críticas. Cavalcanti e Alcadipani (2013) mencionam em seu trabalho quatro dessas críticas: (a) análise limitada das estruturas sociais; (b) postura amoral ao negligenciar questões de cunho político e moral; (c) falha ao considerar a distinção analítica entre humanos e não humanos; e (d) possíveis problemas a respeito de como seguir as entidades numa análise das redes.

Contudo, apesar das críticas à abordagem, observa-se que alguns autores nacionais estão respondendo a essas críticas por meio de avanços teóricos e empíricos que buscam fortalecer a teoria e livrá-la de críticas inconsistentes (Alcadipani \& Tureta, 2009; Tureta \& Alcadipani, 2009, 2011; Tureta \& Araújo, 2013; Tureta, Tonelli, \& Alcadipani, 2011).

\section{Estratégia e redes de governança}

A estratégia como prática social (Golsorkhi, Rouleau, Seidl, \& Vaara, 2010; Jarzabkowski, 2004, 2005; Johnson, Langley, Melin, \& Whittington, 2007; Whittington, 1996, 2004, 2006, 2007) traz a possibilidade de uma melhor descrição do que efetivamente acontece na prática, visto que, às vezes, o que aparece claramente na teoria não se desenvolve da mesma forma no dia a dia das organizações (Montenegro, 2009). Logo, o foco deste trabalho é destacar as atividades e as práticas estratégicas empreendidas pelos atores no seu cotidiano.

Ao traçar um paralelo com a teoria de redes de governança, pode-se afirmar que a noção de estratégia como prática social está alinhada com a lógica que permeia as redes de governança, pois redes dizem respeito a interação, atividade, processo; portanto, à participação ativa dos atores envolvidos. As decisões e as atividades estratégicas ocorrem com base nos entrelaçamentos dos atores e dos conteúdos de que eles tratam. 
Ao falar em governança numa organização educacional, aspectos estratégicos entram no escopo como elementos importantes a serem investigados, pois muito do que é decidido (e do que não é) terá impacto direto nas estratégias traçadas e executadas e nos seus resultados estratégicos. Compreender conteúdo, processo e resultado estratégico sob a lógica da estratégia como prática social parece ser um caminho coerente para entender muitas das questões relativas à governança nas organizações educacionais. Assim, acredita-se que ao mapear os mecanismos e as redes de governança, identificar e compreender a ação dos atores envolvidos e, com isso, trazer à tona explicações sobre essas questões, também estar-se-á tratando de questões estratégicas.

Com relação aos resultados estratégicos, eles são os resultados das atividades e das práticas estratégicas realizadas no cotidiano das organizações pesquisadas. Esses resultados podem ser tangíveis ou intangíveis, e podem contemplar duas dimensões: os resultados almejados e os resultados realizados. A escolha do conjunto de ações articuladas que visam a concretizá-los depende da sua definição e monitoração (Pereira \& Santos, 2001).

Assim como as organizações estudadas foram IES, resultados relativos à qualidade de ensino, ao desenvolvimento de atividades pedagógicas e administrativas, à formação e preparação do corpo docente, à imagem da instituição e às condições de infraestrutura das IES são elementos que poderão aparecer como relevantes na coleta e análise dos dados.

\section{Teoria Ator-Rede e estratégia}

A Teoria Ator-Rede descreve e explica como é possível construir redes de apoio em torno de definições de tecnologia para que elas se tornem aceitas. Diante disso, uma estratégia organizacional pode ser considerada como equivalente a qualquer artefato tecnológico ou a uma descoberta científica. Assim, uma estratégia específica existe na medida em que sua existência torna-se real para a rede de atores organizacionais (humanos e não humanos) que a apoiam. Logo, o processo de fazer estratégia torna-se um processo de translação com todos os elementos potenciais previstos em um processo de translação: problematização; interesse; inscrição e mobilização, levando potencialmente (mas não de forma determinística) para a irreversibilidade de uma estratégia bem-definida (Denis, Langley, \& Rouleau, 2007).

Denis, Langley e Rouleau (2007) enfatizam que ao trabalhar o strategizing e a Teoria Ator-Rede em conjunto, é possível investigar questões relevantes para ambas as teorias, tais como: a mobilização de significados múltiplos e a ligação de múltiplos atores de forma dinâmica. Essa articulação também proporciona o entendimento de como certos objetos adquirem agência (tornam-se actantes) no processo de strategizing. Por exemplo, objetos como planejamentos estratégicos ou fórmulas de alocação de recursos, uma vez constituídos, podem servir para definir ou, pelo menos, para restringir os papéis e as identidades dos atores humanos.

\section{Teoria Ator-Rede, redes de governança e estratégia: uma articulação possível}

Para Kjaer (2004), ao investigar as redes de governança, torna-se necessário entender os papéis dos atores que compõem essas redes. Além de identifica-los, é importante compreender como eles se organizam e quais as suas funções, verificar se existem atores que detêm o poder e entender por que e como os outros lidam com essa situação.

Destaca-se que, na Teoria Ator-Rede e na perspectiva das práticas sociais, o entendimento do poder nas práticas e não a partir de estruturas de governança é fundamental para a análise das redes, pois ele efetivamente auxilia na compreensão dos processos de confiança, cooperação e conflito dessas relações. Além disso, a compreensão de que as relações não são apenas definidas pelas estruturas nem tão pouco se constituem em simples interações, mas são produzidas por meio de ordenações móveis de força, pode contribuir para analisar os imbricamentos em que o social dinamiza o econômico pela disputa e conformação de práticas e não apenas pela formatação de comportamentos (Andrade, 2003). 


\section{Metodologia}

Este trabalho tem como problema de pesquisa a seguinte questão: Como a articulação do strategizing, como processo de translação, com a teoria das redes de governança, configura a governança e os resultados estratégicos de cursos de graduação em Administração de IES particulares de Curitiba? E, como dimensões de análise: (a) o impacto dos mecanismos de governança nos resultados estratégicos das organizações estudadas; (b) a importância dos papéis desempenhados pelos atores humanos e não humanos nos resultados estratégicos das organizações estudadas; (c) a articulação das redes de governança com os atores humanos e não humanos impactando nos resultados estratégicos das organizações estudadas; (d) a relevância das atividades e das práticas estratégicas do cotidiano nos resultados estratégicos das organizações estudadas; e (e) o impacto da dimensão temporal na articulação: redes de governança, atores humanos e não humanos e resultados estratégicos.

A pesquisa tem como justificativa teórica suprir o limite identificado na categoria de análise das redes de governança e aprofundar os estudos de Teoria Ator-Rede e dos resultados estratégicos. Este estudo tem como referência ontológica e epistemológica o entendimento de que a realidade é construída e que, nesse processo, há a participação de múltiplos atores. Entende-se que, na relação sujeito-objeto, subjetivo-objetivo, não há a primazia de um nem de outro.

A natureza do estudo é qualitativa (Kalof, Dan, \& Dietz, 2008). A estratégia de pesquisa é o estudo comparativo de casos (Godoy, 2006) exploratório-descritivo (Neuman, 1997; Saunders, Lewis, \& Thornhill, 2000) com perspectiva temporal transversal com aproximação longitudinal. A unidade de análise são as redes de governança dos casos pesquisados e o nível de análise é o organizacional.

Os dados foram coletados por meio da observação não participante, entrevistas semiestruturadas com os atores envolvidos e pesquisa documental. Os dados foram analisados através de análise de narrativas e Qualitative Comparative Analysis (QCA).

A análise de narrativas, de acordo com Czarniawska (1998), permite que o pesquisador se coloque na interface entre pessoas, histórias, organizações e contexto organizacional e emocional. Segundo Golsorkhi, Rouleau, Seidl e Vaara (2010), a análise de narrativas revela alguns significados e elucida experiências passadas.

Optou-se também por utilizar a análise qualitativa comparativa (QCA) desenvolvida por Ragin (2008) e Rihoux e Ragin (2009), com base no uso da teoria dos conjuntos, que emprega a álgebra booleana como lógica (Fiss, 2007) por alguns motivos. São eles: (a) de acordo com Fiss (2007), as organizações são agrupamentos de estruturas e práticas compostas por relações complexas cujas variáveis produzem resultados diferentes de acordo com a forma de arranjo. Esse autor defende que as únicas metodologias compatíveis com as premissas configuracionais são as que se apoiam na álgebra booleana, tal como a análise qualitativa comparativa (QCA); (b) a abordagem configuracional mostrase relevante para o estudo da administração estratégica devido à sua natureza multidimensional; (c) a QCA geralmente é utilizada para tratar, de forma simultânea, casos com resultados positivos e negativos.

Foram estudados cinco casos e, conforme elucidam Rihoux e Ragin (2009), a zona de pequena amostra (small-N zone) é geralmente associada a um número realmente baixo de casos, o que permite uma forma de comparação binária.

Os informantes-chave foram professores, coordenadores, diretores e secretárias. Entende-se que todos os que participam da organização têm papel importante e influenciam, em menor ou em maior grau, a governança e suas estratégias.

Os casos foram escolhidos por serem relevantes no contexto estudado, por fazerem parte de instituições visadas e por terem em torno de dez anos de atuação institucional. 
A pesquisa foi realizada em cinco IES. Foram realizadas 29 (vinte e nove) entrevistas distribuídas da seguinte forma: (a) Caso A (nove); (b) Caso B (cinco); (c) Caso C (quatro); Caso D (cinco) e Caso E (seis). Essas entrevistas foram gravadas e, posteriormente, transcritas.

Com relação à validade e à confiabilidade deste estudo, destacou-se a triangulação de múltiplas e diferentes fontes; a reflexividade, ao considerar as possíveis inconsistências do estudo; e a volumosa e detalhada descrição dos dados (Paiva, Leão, \& Mello, 2011).

Quanto às limitações do estudo, destaca-se que todo método está sujeito a possibilidades e limitações (Vergara, 2009). Diante disso, é possível que os informantes-chave selecionados para as entrevistas não tenham sido os mais representativos do fenômeno organizacional pesquisado; porém é necessário frisar que qualquer processo de investigação corre esse risco. No que se refere à falta de experiência dos pesquisadores relativa a este tipo de pesquisa, enfatiza-se que este aspecto foi minimizado ao se empreender uma aproximação tanto do campo empírico, quanto da metodologia utilizada, o que trouxe mais segurança para os pesquisadores desenvolverem o trabalho.

\section{Análise dos Dados}

\section{Primeira fase: análise de narrativas}

\section{Narrativa do caso A}

O Caso A é uma instituição pequena, com alguns cursos de bacharelado e alguns cursos de tecnólogo. A instituição é vinculada a uma associação de base religiosa e alguns dos seus funcionários e alunos seguem a mesma religião. A influência da religião é percebida de forma sutil, no que se refere aos princípios e valores compartilhados pelos funcionários. De certa forma, é algo que molda a cultura organizacional da instituição.

Algumas ações da instituição - tais como palestras de aperfeiçoamento e aprendizagem, aulas de nivelamento e incentivo ao desenvolvimento de projetos e cursos de extensão - são realizadas com o intuito de melhorar o desempenho dos alunos, bem como o aprendizado de professores e estudantes no que se refere ao desenvolvimento de projetos de extensão.

Com base no que foi mencionado pela maioria dos entrevistados, não se percebe uma estratégia consensualmente definida; contudo, observa-se claramente que a instituição busca sobreviver.

Assim, pode-se inferir que essa noção de sobrevivência se configura como um posicionamento estratégico, uma vez que as relações entre os atores, as atividades e as práticas estratégicas realizadas no dia a dia organizacional e as decisões tomadas pela gestão da instituição são questões que expressam esse fazer estratégico (strategizing).

Em meio a diversas atividades e práticas estratégicas realizadas para a busca da sobrevivência, tais como: resgate de conteúdo para os alunos que estão com dificuldades, integrações entre direção, professores e alunos (exemplo: projetos de extensão, semana pedagógica, palestras, visitas a empresas e capacitação de professores), os atores envolvidos com a instituição percebem que o mercado é acirrado. Diante disso, o aluno que procura uma instituição privada para fazer um curso superior ou um curso de tecnólogo é alguém que tem algumas dificuldades (tanto financeiras, quanto de aprendizagem). Já a instituição passa por uma cobrança constante do Ministério da Educação (MEC).

A instituição busca, diariamente, driblar as dificuldades financeiras, pois os incentivos existentes por meio do FIES e do PROUNI deixam a desejar. Todavia, apesar de todas essas dificuldades, pretende criar as condições para se tornar centro universitário. 
Nota-se que existem objetivos a serem alcançados: fala-se, brevemente, no planejamento estratégico, e percebe-se que a nova gestão preocupa-se com a saúde da instituição, visto que busca cumprir os requisitos solicitados pelo MEC e se organizar da melhor forma possível para continuar sobrevivendo. Vê-se a importância das diversas atividades e práticas estratégicas empreendidas pelos atores da instituição; porém, acredita-se que um pouco mais de autonomia e de uma articulação mais integradora dos mecanismos de governança seriam necessários para auxiliar o processo do fazer estratégico (strategizing) da instituição.

Com relação aos atores envolvidos, os atores humanos que mais se destacam são a diretora da instituição, os coordenadores do curso, os professores, o corpo técnico (funcionários da instituição que não são diretor/coordenador/professor) e os alunos. A coordenadora do curso se mostra engajada nas atividades e práticas diárias dos professores e alunos, uma vez que busca a aproximação dos docentes por meio de contato pessoal ou por e-mail, e também recebe os alunos quando eles a procuram. A diretora é presente e busca estar a par dos problemas. A participação dos atores envolvidos ocorre por meio de práticas formais - reuniões de colegiado, reuniões do Núcleo Docente Estruturante (NDE), bem como por meio de práticas informais - reuniões individuais e pontuais com a coordenação do curso e troca de e-mails. O NDE de um curso de graduação é formado por um grupo de docentes com atribuições acadêmicas de acompanhamento, atuante no processo de concepção, consolidação e contínua atualização do projeto pedagógico do curso.

Quanto aos atores não humanos, destaca-se a instituição MEC. Muitas das questões que são decididas e das atividades e práticas estratégicas dos atores entrevistados estão atreladas às exigências e às cobranças do MEC. A presença desse ator não humano é constante, e ele desenvolve um papel crucial na instituição. Todavia, o Ministério da Educação algumas vezes é percebido de forma diferenciada por parte dos atores humanos. Para alguns, ele é importante, deve existir ou seria pior se ele não existisse. Para uns, ele é muito exigente. Para outros, é desorganizado.

Além do MEC, observam-se outros atores não humanos relevantes, tais como: o projeto político pedagógico, o planejamento estratégico e o regimento interno do curso de Administração. A importância desses atores ocorre não simplesmente pelo fato de que há, em cada um desses documentos, conteúdos sistematizados que serão úteis à instituição como um todo, mas porque eles sugerem momentos de interação que aconteceram a priori - reuniões formais e informais, atividades relativas à forma de reunir as informações que estão nesses documentos, entre outros. Portanto, acredita-se que o strategizing da instituição se revela nos momentos formais e informais.

Conforme apresenta Jarzabkowski (2005), as práticas estratégicas podem ser administrativas, discursivas e episódicas. Então, documentos formais podem ser considerados práticas administrativas; o que se discute na instituição sobre as questões estratégicas, a maneira como os atores articulam seus interesses, opiniões e divergências, por meio da linguagem, podem ser consideradas práticas discursivas e as reuniões de colegiado, reuniões do NDE, palestras e semana pedagógica podem ser consideradas práticas episódicas.

Percebe-se que o processo de strategizing acontece, principalmente, por meio da mobilização de significados múltiplos e da ligação de múltiplos atores de forma dinâmica. Essa articulação também proporciona o entendimento de como certos objetos adquirem agência (tornam-se actantes) no processo de strategizing. Por exemplo, objetos como o planejamento estratégico, o projeto político pedagógico, o MEC e até mesmo as redes de governança identificadas podem servir, em alguns momentos, para definir e, em outros momentos, para restringir os papéis e as identidades dos atores humanos.

No Caso A, percebe-se que não há uma estratégia efetivamente delineada. Alguns atores acreditam que deve haver uma preocupação com a qualidade dos docentes e dos discentes, outros acreditam que o objetivo da instituição é tornar-se centro universitário. Apesar de não haver um pensamento estratégico único, percebe-se que as atividades e práticas estratégicas realizadas pelos atores envolvidos estão relacionadas à sobrevivência e, de certa forma, nesse fato se configura sua forma de fazer estratégia (strategizing). 
Quanto à governança, no que se refere aos mecanismos internos, foi possível identificar uma grande rede formada pelos seguintes elos: (a) direção-coordenação; (b) direção-docentes; (c) direçãodiscentes; (d) direção-demais funcionários; (e) coordenação-docentes; (f) coordenação-discentes; (g) docentes-discentes. As redes possuem formações estáveis, sempre que há alguma disfunção ou conflito, a rede é reconfigurada. O ajuste maior aconteceu quando houve a mudança de gestão e a atual direção optou por rearranjar ou até mesmo dispensar alguns atores da rede interna. Portanto, os elos direçãocoordenação; direção-docentes, direção-discentes e direção-demais funcionários são fortemente articulados. A proximidade da direção da IES com os outros atores da instituição é uma característica peculiar do Caso A e é um fator relevante para compreender a gestão da IES, bem como sua cultura.

Com relação aos mecanismos de governança atrelados a questões externas, há uma rede fortemente construída que pode ser definida como Caso A - MEC. É uma rede formalmente criada em que estão definidos claramente os papéis e as atribuições de cada integrante. O relacionamento é fortalecido pela frequência com que um elo precisa do outro, visto que tanto a instituição procura o MEC e está em contato constante com ele - de forma direta por meio de representantes e avaliadores; e de forma indireta por meio de contatos via e-mail, site, telefone, entre outros, quanto o MEC está presente com frequência em visitas de avaliação do curso e portarias com atualizações e/ou alterações de normas e regulamentos.

As redes internas e externas geram novas relações, e essas novas relações se mostram indispensáveis para as ações e as decisões importantes das IES estudadas. Enfatiza-se que há interesse mútuo quando da formação de uma rede entre instituições. A dissolução dessas redes acontece quando não há mais o interesse em manter o relacionamento por parte de um ou mais integrantes da rede.

Nota-se que tais relações podem ter influência direta nos resultados estratégicos das instituições, visto que as ações e as decisões dos atores responsáveis fazem parte do processo de strategizing das organizações. Portanto, o movimento dessas redes e dessas relações se configura como algo importante para compreender a governança das instituições.

No que diz respeito aos resultados estratégicos, são aqueles relativos aos resultados das atividades e práticas estratégicas desenvolvidas pelos atores na busca pela sobrevivência da instituição.

Esses resultados aparecem em situações como: (a) resultado bem sucedido de resgate de alunos com dificuldades em disciplinas específicas, proporcionando, com isso, uma motivação para esse aluno o que poderá acarretar uma adesão maior ao curso, diminuindo a evasão; (b) fortalecimento da integração entre direção, coordenação, corpo docente e corpo discente por meio de práticas episódicas, como reuniões, semana pedagógica, participação em projetos de extensão; (c) cumprimento das normas do MEC e melhoria da qualidade dos cursos da instituição por meio de boas avaliações, cursos autorizados e reconhecidos; (d) a busca por um corpo docente coeso e qualificado (tentativas constantes de integrar o grupo, e a contratação mais frequente de professores com título de doutorado).

A questão da sobrevivência sugere que os atores humanos e não humanos estão constantemente engajados em ações, decisões, atividades e práticas.

\section{Narrativa do caso B}

A instituição (Caso B) foi fundada na década de 50. Desde a sua fundação, com base em princípios socialmente responsáveis, confirma sua história de perseverança e de vocação educacional, tal como idealizada por seus fundadores.

Ao longo de seu processo de transformação, a instituição, que iniciou suas atividades com o Curso de Direito, tornou-se, em 2007, Centro Universitário.

O planejamento estratégico foi mencionado pelos entrevistados; contudo, de forma muito superficial. A mudança de coordenador é constante. Alguns mencionam que o objetivo do curso é proporcionar um ensino de qualidade aos alunos, ter professores capacitados e qualificados. Essa 
questão da qualidade aparece com certa frequência. Muitos dos entrevistados, ao se referirem à qualidade, mencionam que essa é uma característica almejada pelos dirigentes. Comumente ocorre a comparação com o curso de Direito, visto que é um curso bem avaliado e procurado pelos alunos. $\mathrm{O}$ centro universitário tem condições de oferecer uma boa estrutura. Então, a boa estrutura, aliada à fama do curso de Direito e ao fato de alguns professores estarem há bastante tempo no curso, faz com que eles consigam uma boa posição no mercado. A mensalidade tem valor elevado, e a instituição procura atrair bons alunos.

Quanto aos atores identificados no Caso B, os atores humanos que mais se destacam são os coordenadores de curso, os que compõem a direção da instituição, os professores e os alunos. Segundo os entrevistados, os professores não são comprometidos. Há alguns professores que trabalham há muito tempo na instituição, mas não são muitos. Boa parte do corpo docente tem outra ocupação durante o dia e vai para a instituição à noite exclusivamente para ministrar suas aulas. Muitos deles não participam de reuniões e permanecem o mínimo de tempo possível na semana pedagógica. Os coordenadores dos cursos procuram manter uma boa relação com eles, mas, com base no que foi mencionado por alguns entrevistados, essa relação é difícil, pois os coordenadores reclamam da falta de comprometimento dos professores.

Quanto aos atores não humanos, o destaque maior é da instituição MEC, uma vez que todos os entrevistados mencionam a sua importância. Além do MEC, outros atores não humanos - como o projeto pedagógico do curso e os planos de ensino das disciplinas - também possuem um papel de destaque no Caso B. Práticas episódicas e práticas administrativas que envolvem pensar, discutir, decidir e pôr em prática o projeto pedagógico do curso e o planejamento estratégico, por exemplo, são momentos em que é possível perceber o strategizing do Caso B.

Com base na maioria das entrevistas, nas observações não participantes e nos documentos coletados, nota-se que o processo de strategizing como processo de translação acontece de forma que se percebe uma reflexividade entre os praticantes, uma vez que estudos com base na Teoria Ator-Rede preveem esse tipo de prática. Então, apesar da falta de comprometimento de alguns professores e do pouco tempo dedicado às atividades e práticas estratégicas além da sala de aula, os praticantes mais ativos compartilham opiniões, posicionamentos e atitudes que conferem ao Caso B um status de um curso de graduação em processo de consolidação.

Alguns entrevistados sugerem que não há uma estratégia consensualmente definida, outros acreditam que há uma preocupação, por parte da direção, com a qualidade do ensino, outros sugerem que o curso busca o seu lugar no mercado competitivo das IES particulares de Curitiba e outros, ainda, mencionam, brevemente, o planejamento estratégico.

Observa-se que, apesar do Caso B não possuir clareza e/ou consenso no que se refere aos seus objetivos futuros, há um movimento importante atrelado a atividades e práticas estratégicas, tais como: a busca por parcerias com outras instituições, associações e órgãos para aumentar os contatos da instituição e possibilitar o desenvolvimento de atividades diferenciadas para a instituição e boas palestras; a busca por ter um corpo docente competente e também a tentativa de atrair alunos competentes e comprometidos. Diante dessas questões, observa-se que o Caso B está disposto a se consolidar no mercado.

No que diz respeito às redes internas de governança, estes são os elos existentes no Caso B: (a) direção-coordenação; (b) coordenação-docentes; (c) coordenação-discentes; e (d) docentes-discentes. Esses elos mostram pontos de fragilidade, visto que há a falta de comprometimento e interação por parte dos elos: coordenação-docentes e docentes-discentes. Além disso, há uma dissolução frequente dessa rede, principalmente no elo coordenação-docentes, uma vez que a mudança de coordenador é constante. A rede, ao ser reconfigurada, sofre algumas perdas, principalmente com relação à identidade, segurança, alinhamento de gestão e estratégia.

Com relação aos mecanismos de governança atrelados a questões externas, o MEC possui papel decisivo. O Caso B possui um funcionário responsável por lidar exclusivamente com as questões 
relativas ao MEC. Além da rede constituída com a influência do MEC, também há a relação com a Associação Comercial, uma vez que o coordenador busca desenvolver relações próximas com essas instituições, as quais sejam úteis para ambas as partes.

Os resultados estratégicos são aqueles decorrentes das atividades e práticas estratégicas empreendidas pelos praticantes, tais como: (a) as parcerias bem sucedidas conquistadas pela coordenação do curso que são positivas para a instituição, uma vez que fomentam palestras, aproximam os alunos das empresas, entre outros; (b) a busca por manter e contratar professores comprometidos com a instituição e que são mestres e doutores, proporcionando, assim, um ensino de qualidade aos alunos; e (c) um acompanhamento próximo dos alunos no que diz respeito ao seu aprendizado, na estruturação da sua grade horária e na orientação dos trabalhos de TCC.

\section{Narrativa do caso C}

De acordo com as informações referentes ao Caso C, a instituição possui curso de graduação, pósgraduação e cursos a distância.

Com base no que foi mencionado pelos entrevistados, não há uma estratégia consensualmente definida. A instituição está buscando se consolidar. Os entrevistados percebem o mercado como competitivo e acirrado, visto que há muitos centros universitários atuando, seus alunos possuem dificuldades financeiras e de aprendizagem, e incerteza quanto ao curso que querem fazer, além do fato que a instituição passou, recentemente, por uma mudança de gestão e ainda está ajustando algumas questões relativas às atividades e às práticas estratégicas desenvolvidas no dia a dia.

Com relação aos atores envolvidos, os atores humanos que mais se destacam são os professores, a coordenadora do curso de graduação em Administração e os alunos. Os professores demonstram comprometimento não apenas com a instituição, mas também com a Educação como um todo. Alguns dos entrevistados trabalham há dez anos na instituição e percebe-se que eles fazem o possível para cumprirem efetivamente o papel de educadores. Eles se preocupam com as aulas que irão ministrar, buscam os melhores materiais e conteúdos, interessam-se pelo desempenho dos alunos e acreditam que o relacionamento com a coordenação é indispensável para executarem bem suas atividades e práticas. A coordenadora é engajada nas atividades e práticas diárias dos professores e alunos. Para ela, muitos desses fatores são relevantes para a condução, a gestão e o direcionamento do curso.

Quanto aos atores não humanos, o destaque maior é da instituição MEC. Para alguns, ele é importante e desempenha um bom papel. Para outros, é exigente. Para outro grupo, ele é apenas um órgão burocrático. Apesar dessas diferenças, aparece como um ator não humano relevante e merece o seu destaque nesta pesquisa.

Com base na maior parte das entrevistas, nas observações não participantes e nos documentos coletados, percebe-se que o strategizing como processo de translação acontece de forma dinâmica por meio dos múltiplos significados mobilizados pelos atores envolvidos. Nesse processo, nota-se a importância da agência dos atores humanos e dos atores não humanos. Algumas práticas formais - como o projeto político pedagógico e a formulação da matriz curricular - se configuram como práticas relevantes que, de certa forma, definem ou restringem os papéis e as identidades dos atores humanos envolvidos, visto que os movimentos dos atores - integração, participação, afastamento, comprometimento, discordâncias - no desempenhar dessas práticas são essenciais para a compreensão do strategizing.

Assim, o strategizing, compreendido nesta pesquisa como um processo de translação, e, portanto, uma interação que prevê a construção de definições e significados comuns, requer a cooperação de todos os envolvidos na busca por objetivos individuais e coletivos.

Quanto à governança, no que se refere aos mecanismos internos, ela é formada por direção, coordenação, docentes e discentes. Percebe-se a falta de comprometimento e interação por parte dos elos: direção-professores e direção-alunos. A fragilidade dessa rede de governança pode ser percebida 
com base no distanciamento que há entre a direção da instituição e os coordenadores, professores e alunos. Houve uma mudança recente de gestão e, por isso, essa rede ainda está em processo de consolidação, apresentando aspectos frágeis e instáveis.

No que diz respeito aos resultados estratégicos, são os decorrentes das atividades e práticas estratégicas empreendidas pelos praticantes, tais como: (a) a busca por uma integração efetiva com os professores; (b) a busca por promoção de atividades e eventos extraclasse; e (c) o trabalho comprometido da coordenadora. Assim, observa-se, conforme o que foi mencionado pelos entrevistados, que a instituição está buscando se consolidar.

\section{Narrativa do caso $D$}

A instituição do Caso D faz parte de um grupo maior, o qual possui seis unidades. Esta pesquisa foi realizada em uma unidade do centro de Curitiba. Alguns entrevistados mencionaram que a estratégia da instituição é oferecer um serviço de qualidade (entregar um serviço de qualidade para a sociedade, atender às necessidades do mercado de trabalho, ter cada vez mais alunos), outros mencionam que a estratégia é oferecer uma "educação sem barreiras", outros mencionam que a estratégia é se tornar uma universidade, já outros mencionam que a estratégia é inserir novos cursos. Observa-se que cada um percebe a estratégia da instituição de forma diferente, não há um consenso em relação a isso. Alguns mencionam que a gestão é falha em diversos aspectos, sendo a questão estratégica um deles.

Quanto aos atores envolvidos, os atores humanos que mais se destacam são os coordenadores, os professores, o corpo técnico e os alunos, portanto, a maioria das pessoas que compõem a instituição. Todos têm a sua devida importância, compõem a rede de governança interna da instituição e participam das atividades e práticas estratégicas da instituição. Os coordenadores dos cursos procuram manter uma boa relação com os professores. Há uma relação formal entre coordenadores e professores, mas é possível inferir que essa relação é harmoniosa, e não foi possível perceber atritos e dificuldades de relacionamento. A participação dos atores envolvidos acontece por meio de práticas formais - reuniões de colegiado e reuniões do NDE, por exemplo, bem como por meio de práticas informais - reuniões individuais específicas e troca de e-mails.

Já o ator não humano que possui mais destaque é o MEC. Muitas das questões que são decididas e das atividades e práticas diárias dos entrevistados estão atreladas às exigências e às cobranças do MEC. Para alguns, ele é necessário. Para outros, ele é exigente ou até mesmo extremamente exigente. E, às vezes, até pode ser considerado fonte e causa de ameaça. Apesar dessas diferenças, ele aparece como um ator não humano relevante nesta pesquisa.

No Caso D, o strategizing como processo de translação acontece por meio de mobilizações de significados diversos dos atores que estão atuando no processo de forma dinâmica. Percebe-se, nessa articulação, a importância da atuação de ambos os atores, humanos e não humanos que, de certa forma, ganham vida no processo de strategizing, uma vez que, na relação com o ator humano, há sempre um confronto envolvendo consenso, controvérsias, dúvidas, explicações, entre outros.

Nesta IES, foi possível identificar a importância de questões relativas aos materiais didáticos utilizados pelos professores (como os professores se apropriam desses materiais que foram discutidos, pensados e repensados por outros atores humanos da instituição).

No que diz respeito aos resultados estratégicos, destacam-se os seguintes: (a) a busca constante por ter um ambiente integrado, onde as pessoas possam ter acesso imediato às outras pessoas; (b) ter um setor específico para atender - da melhor forma possível e com rapidez - os alunos. Assim, acredita-se que o Caso D esteja buscando se consolidar no mercado. 


\section{Narrativa do caso $E$}

O Caso E iniciou suas atividades no ensino superior em 1994. Atualmente, oferece os cursos de Bacharelado em Administração de Empresas, Ciências Contábeis e Sistemas de Informação; além de Pós-Graduação Lato Sensu e Extensão Universitária em diversas áreas.

Com relação aos atores humanos que mais se destacam são os professores, a diretora da instituição, a coordenadora do curso de graduação em Administração e os alunos. Conforme os dados obtidos, questões relativas à atualização do professor na atividade de docência, sua didática e alguns documentos, como o projeto político pedagógico, configuram-se como atores não humanos relevantes deste caso, uma vez que esses fatores fazem parte das atividades e práticas estratégicas dos professores e, consequentemente, compõem o processo de strategizing.

Com base no que foi mencionado pelos entrevistados, não há um consenso em relação à estratégia do Caso E. A instituição busca sobreviver. Eles acreditam que o mercado das IES de Curitiba é muito competitivo, o aluno que procura uma instituição privada para fazer um curso superior é um aluno que tem algumas dificuldades (em alguns casos, a dificuldade é financeira, em outros a dificuldade é de aprendizagem e ainda há casos em que são ambas as dificuldades). A instituição pesquisada busca, diariamente, driblar as dificuldades financeiras. Alguns entrevistados mencionam a localização como algo estratégico. Outros mencionam que o objetivo da instituição é prover um ensino de qualidade aos alunos.

Nota-se que a participação dos atores envolvidos acontece não apenas por meio de práticas formais - reuniões de colegiado, reuniões do NDE, por exemplo, mas também por meio de práticas informais - conversas nos cafés da manhã e almoços promovidos pela instituição, reuniões individuais específicas e trocas de e-mails.

Com relação aos atores não humanos, o MEC aparece na pesquisa como o mais relevante. A presença desse ator não humano é constante, visto que ele desenvolve papel crucial dentro da instituição. Apesar da sua presença constante, ele, algumas vezes, é percebido de forma diferenciada por parte dos atores humanos. Para alguns, ele é importante, desempenha um bom papel. Para outros, é exigente. Para outro grupo, age de forma injusta.

Além do MEC, existem outros atores não humanos importantes na instituição, tais como alguns documentos e materiais - projeto político pedagógico do curso, matriz curricular, materiais didáticos visto que a elaboração, a modificação e a atualização desses documentos e materiais são ações que mobilizam bastante a integração, as práticas episódicas (reuniões, palestras, entre outros) dos atores envolvidos e, por buscar proporcionar um ensino de qualidade aos alunos, configuram-se como elementos importantes do processo de strategizing da instituição.

A governança, no que se refere aos mecanismos internos (redes de governança internas), acontece de forma clara e integrada. A rede de governança interna é bastante sólida e articulada. Percebe-se que os elos direção-coordenação, coordenação-professores, coordenação-alunos, professores-alunos, direção-professores e direção-alunos são fortes. Todos estão comprometidos com o bem-estar da instituição e com a qualidade dos seus cursos.

Com relação aos mecanismos de governança atrelados a questões externas, há uma rede fortemente construída: o Caso E - MEC. Existem outras iniciativas promovidas pela instituição no sentido de fortalecer suas parcerias e relacionamentos com empresas diversas. Essas relações são estabelecidas no momento em que os alunos desenvolvem seus projetos integradores (projetos desenvolvidos durante seus cursos) em organizações dos setores público e privado da cidade de Curitiba.

Os resultados estratégicos identificados neste caso são decorrentes das atividades e práticas estratégicas desenvolvidas pelos praticantes da instituição, tais como: (a) o empenho por criar um ambiente agradável de trabalho, facilitando, assim, a integração da direção, da coordenação, de professores e alunos; (b) a luta por um ensino de qualidade; e (c) a aproximação com o meio empresarial. 
Assim, percebe-se que a instituição está sempre procurando desenvolver práticas e atividades que a auxiliem na busca pela sobrevivência.

\section{Segunda fase: análise qualitativa comparativa (QCA)}

Conforme elucidam Rihoux e Ragin (2009), a zona de amostra pequena (small-N zone) requer manter uma quantidade baixa de condições. As condições analisadas na fase 1 estão organizadas, com seus devidos desdobramentos (valores), juntamente com os seus resultados dicotômicos. Ver Tabela 1.

Tabela 1

\section{Condições, Configurações e Resultado Dicotômico}

\section{Condições/Configurações e Resultado Dicotômico}

\begin{tabular}{cl}
\hline A. & Perfil do Docente \\
\hline 0 & Mais voltado para o mercado \\
1 & Mais voltado para o meio acadêmico \\
2 & Dedicação ao mercado e ao meio acadêmico é igualmente proporcional \\
\hline B. Situação das Faculdades/Centro Universitários de Curitiba \\
\hline 0 & Estável bom \\
1 & Estável ruim \\
2 & Ruim \\
\hline C. Estratégia/Strategizing \\
\hline 0 & Clareza estratégica \\
1 & Falta de clareza estratégica \\
2 & Estratégia inexistente \\
\hline D. Redes de Governança \\
\hline 0 & Redes fortemente articuladas \\
1 & Redes fracamente articuladas \\
2 & Redes dinâmicas \\
\hline E. MEC \\
\hline 0 & Bom. Cumpre o seu papel \\
1 & Exigente (muito exigente) \\
2 & Exigente (injusto) \\
\hline F. Ambiente interno/Cultura Organizacional \\
\hline 0 & Bom. Tranquilo. Agradável \\
1 & Desconfortável. Competitivo \\
2 & Neutro \\
\hline
\end{tabular}




\section{Tabela 1 (continuação)}

\section{Condições/Configurações e Resultado Dicotômico}

\section{R. Resultado Dicotômico}

0 Sobrevivência

1 Consolidação

Nota. Fonte: elaborado pelos autores com base em Rhodes, R. A. W. (1997). Understanding governance: policy networks, governance, reflexivity and accountability. New York: Open University Press; Rhodes, R. A. W. (2007). Understanding governance: ten years on. Organization Studies, 28(8), 1243-1264. doi: 10.1177/0170840607076586; Rhodes, R. A. W. (2011). Thinking on: a career in public administration. Public Administration, 89(1), 196-212. doi: 10.1111/j.1467-9299.2011.01898.x; Latour, B. (1994b). Pragmatogonies: a mythical account of how humans and nonhumans swap properties. American Behavioral Scientist, 37(6), 791-808. doi: 10.1177/0002764294037006006; Latour, B. (1996). On interobjectivity. Mind, Culture and Activity, 3(4), 228-245. doi: 10.1207/s15327884mca0304_2; Latour, B. (2000). Ciência em ação: como seguir cientistas e engenheiros sociedade afora. São Paulo: Editora UNESP; Latour, B. (2001). A esperança de Pandora: ensaios sobre a realidade dos estudos científicos. Bauru, SP: EDUSC; Latour, B. (2005). Reassembling the social: an introduction to atornetwork-theory. New York: Oxford University Press; Johnson, G., Langley, A., Melin, L., \& Whittington, R. (2007). Strategy as practice: research directions and resources. New York: Cambridge University Press; Golsorkhi, D., Rouleau, L., Seidl, D., \& Vaara, E. (Eds.). (2010). Cambridge handbook of strategy as practice. Cambridge: Cambridge University Press; Matitz, Q. R. S. (2009). Aspectos semânticos, formais e funcionais do conceito desempenho em estudos organizacionais e estratégia: um modelo analítico (Tese de doutorado). Universidade Federal do Paraná, Curitiba, PR, Brasil; Bulgacov, S., Souza, Q. R., Prohmann, J. I. P. de, Coser, C., \& Baraniuk, J. (2007). Administração estratégica: teoria e prática (Col. P. J. Pires). São Paulo: Atlas; e nos dados empíricos.

Com relação às condições que foram criadas, cada uma delas foi elaborada com base em uma escala multicategórica com três valores $(0,1,2)$. Conforme se apresentou na Tabela 1 , foram criadas 6 (seis) condições (A, B, C, D, E, F). Com relação ao resultado (R), que precisa ser dicotômico, foram criados dois valores $(0,1)$. Diante disso, optou-se por escolher 3 (três) das condições que se mostraram mais significativas para explicar as categorias de análise, uma vez que, na técnica mvQCA, deve-se usar um máximo de 5 (cinco) condições. As condições escolhidas foram: (a) C. Estratégia e Strategizing; (b) D. Redes de Governança e (c) E. MEC.

Com essas condições, o resultado e a lista de casos foi possível alimentar o software Tosmana (Cronqvist, 2007) e gerar alguns resultados.

Nos resultados, formaram-se três agrupamentos (1- Caso A, Caso E; 2- Caso B, Caso D; 3- Caso C). Destaca-se que os Casos B, C e D tinham o valor de resultado (1) e os Casos A e E tinham o valor de resultado (0). Mesmo com o mesmo resultado de B e D, o Caso C ficou isolado em outro agrupamento. Portanto, com valores diferentes nas variáveis condições, obteve-se o mesmo resultado. De acordo com De Meur e Rihoux (2002), caminhos causais diferentes - cada caminho sendo relevante, de forma distinta - podem levar ao mesmo resultado. Essa é a noção de equifinalidade.

Conforme explicam Rihoux e Ragin (2009), com o QCA, se uma combinação de condições explica apenas um único caso, a priori, esse caso não é considerado como menos relevante do que outra combinação de condições - porque cada caso importa na maioria das aplicações de QCA.

Com relação aos três agrupamentos formados, a Tabela 2 apresenta as características de cada agrupamento: 
Tabela 2

\section{Agrupamento dos Casos Estudados e suas Descrições}

\begin{tabular}{|c|c|c|c|}
\hline & Nome & Casos & Descrição \\
\hline 1 & $\begin{array}{l}\text { Agrupamento } \\
\text { Sobreviver } \\
\text { preciso }\end{array}$ & $\begin{array}{l}\text { Caso A } \\
\text { Caso E }\end{array}$ & $\begin{array}{l}\text { Com base em redes de governança articuladas e uma cultura organizacional } \\
\text { com características de aproximação e cooperação, essas faculdades estão } \\
\text { buscando sobreviver em meio à falta de clareza estratégica e às dificuldades, } \\
\text { não apenas financeira, mas também relativas à falta de comprometimento de } \\
\text { alguns docentes e discentes. }\end{array}$ \\
\hline 2 & $\begin{array}{l}\text { Agrupamento } \\
\text { Consolidação, pois } \\
\text { temos tudo nas } \\
\text { mãos }\end{array}$ & $\begin{array}{l}\text { Caso B } \\
\text { Caso D }\end{array}$ & $\begin{array}{l}\text { Apesar de possuírem redes de governança fracamente articuladas e falta de } \\
\text { clareza estratégica, esses centros universitários buscam a consolidação de } \\
\text { seus cursos, perante o mercado e as outras instituições com as quais se } \\
\text { relacionam, com base em fatores como: possuem um nome consolidado, } \\
\text { bons professores e alunos, situação financeira razoável e boa estrutura física. }\end{array}$ \\
\hline 3 & $\begin{array}{l}\text { Agrupamento } \\
\text { Consolidação com } \\
\text { base na integração }\end{array}$ & Caso C & $\begin{array}{l}\text { Com base em redes de governança fracamente articuladas, principalmente } \\
\text { nos elos que envolvem a direção do curso - uma vez que houve uma mudança } \\
\text { de gestão recente - e com um strategizing pautado principalmente em } \\
\text { questões de envolvimento e integração, esse centro universitário busca se } \\
\text { consolidar, perante o mercado e as outras instituições com as quais se } \\
\text { relaciona, amparando-se em alguns professores comprometidos e em uma } \\
\text { coordenação proativa. }\end{array}$ \\
\hline
\end{tabular}

Nota. Fonte: elaborado pelos autores com base nos dados de pesquisa e nas análises feitas no software Tosmana (Cronqvist, L. (2007). Tosmana - Tool for small-N analysis (Version 1.3) [Software]. Marburg, Hesse, Alemanha. Recuperado de http://www.tosmana.net).

Portanto, perante os agrupamentos formados, percebe-se que os Casos A e E possuem resultados estratégicos pontuais, pautados em questões decorrentes de uma cultura organizacional forte e integrada, uma vez que acreditam que essa integração, esse envolvimento e, consequentemente, esse comprometimento com as atividades e as práticas estratégicas realizadas na instituição são a base para sua sobrevivência. E, onde se geram resultados de ensino de qualidade. Assim, conclui-se que para se alcançar um resultado consistente, é preciso que haja a participação de todos. As pessoas precisam se sentir parte do processo. De nada adianta ter um bom preparo de aula (conteúdo atualizado, boa didática), se o professor não se sente parte do todo no qual ele está imerso.

Quanto aos Casos B e D, percebe-se que há estrutura física, de professores e alunos favoráveis a esses casos. Todavia, observou-se que essas condições não são suficientes para que tais casos sejam bem-sucedidos e alcancem um ensino de qualidade, formando profissionais bem preparados e qualificados para o mercado de trabalho. Pode-se inferir que esses cursos ainda não estão consolidados porque algumas de suas redes de governança não são fortemente estabelecidas, visto que, em algumas atividades e práticas estratégicas, não há o envolvimento dos praticantes. Alguns professores só frequentam a instituição no período em que lecionam suas aulas. Percebe-se que o não envolvimento do professor se reflete na sala de aula também. O professor que não participa ativamente das atividades e práticas do dia a dia da instituição, não compartilha algumas informações - geradas nos momentos importantes - com os alunos, ou seja, muitas vezes eles não participam ativamente do processo de strategizing da instituição, uma vez que não mobilizam múltiplos significados constituídos nesse processo.

Por fim, com relação ao Caso C, nota-se que esta instituição também está buscando se consolidar no mercado, mas de forma diferente dos Casos B e D. O Caso C busca a consolidação por meio de resultados provenientes de uma relação claramente integradora entre coordenação do curso e corpo docente. No Caso C, a integração e a cooperação existentes nesse elo da rede interna de governança se configuram como a mola propulsora das atividades e práticas estratégicas da instituição e, por meio dessa relação fortemente firmada e dinâmica, podem-se observar resultados de ensino positivos. A busca 
pela consolidação ainda está em andamento porque algumas questões relativas à gestão da instituição estão passando por atualizações e adaptações, uma vez que esta mudou recentemente.

\section{Considerações Finais}

A proposta de se estudar as IES particulares de Curitiba demonstra o interesse em pesquisar um campo permeado por complexidades, adversidades e controvérsias. Conforme enfatiza Barroso (1996), o estudo da escola como organização levou a reformulações teóricas e metodológicas que constituem um campo estimulante do debate científico.

Diante dessas questões, esse estudo buscou atender uma demanda de pesquisa desse campo, uma vez que Laderrière (1996) ressalta que estudos sobre a escola como organização devem ser estimulados, visto que se trata de uma realidade organizacional em que modelos explicativos não são facilmente desenvolvidos, e que ainda há muito a se investigar para saber ao certo que políticas e práticas devem ser adotadas nesse contexto. Há muitas incertezas nesse campo, então estudos relevantes podem evitar o prolongamento dessas questões ambíguas.

A principal contribuição da articulação teórica desenvolvida neste trabalho refere-se ao avanço teórico proposto à teoria das redes de governança com base em concepções da Teoria Ator-Rede, principalmente em relação à incorporação do entendimento dos atores não humanos no arcabouço teórico da teoria das redes de governança. O entendimento ampliado desta teoria também corrobora a perspectiva da estratégia como prática social, uma vez que esta abordagem está pautada em atividades e práticas desenvolvidas por múltiplos atores.

As teorias tratadas neste trabalho foram escolhidas primeiramente com base em uma preocupação epistemológica: acredita-se que a realidade é construída por múltiplos atores. Optou-se por compreender e revelar questões relativas à sociomaterialidade; logo, a Teoria Ator-Rede foi uma das destacadas. A teoria das redes de governança foi escolhida por interesse dos pesquisadores em investigar questões relativas à governança e aos seus mecanismos no âmbito das IES e, por fim, para compreender as questões estratégicas, a abordagem da estratégia como prática social se mostrou apropriada para investigar o fenômeno organizacional, tendo como praticantes os diferentes atores envolvidos.

Assim, diante de um arcabouço criado com base em três teorias amplas, buscou-se desenvolver a articulação teórica sabendo que outros níveis de análise e outros elementos teóricos de outras teorias não seriam contemplados nesta pesquisa. A Teoria Institucional, por exemplo, poderia revelar questões importantes, principalmente relativas ao isomorfismo e à legitimidade. Contudo, a proposta desta pesquisa era diversa, com interesse de aprofundar, ampliar e reforçar outros aspectos teóricos que não os contemplados pela Teoria Institucional.

Destaca-se também que a pesquisa não é multinível e não buscou compreensões no nível institucional, preferindo tecer suas considerações teóricas e analíticas no nível meso de análise. Mais especificamente, no nível organizacional.

Neste trabalho foi possível perceber a forte atuação do MEC, bem como a importância do projeto político pedagógico dos cursos de graduação em Administração estudados e das redes de governança configurando-se como atores não humanos relevantes. Observou-se também a importância das atividades e práticas estratégicas relacionadas aos mecanismos e às redes de governança identificados.

Assim, acredita-se que diferentes estudos possam ser delineados com base nesses achados. Além disso, outros estudos podem ter o formato semelhante, mas serem realizados em outros campos de pesquisa ou em outros locais. Dessa forma, sugerem-se as seguintes pesquisas futuras: (a) trabalhar o mesmo arcabouço teórico (governança-redes de governança, estratégia como prática social-strategizingresultados estratégicos e Teoria Ator-Rede - atores humanos e não humanos), no mesmo campo de pesquisa (cursos de graduação em IES particulares); contudo, empreender uma imersão longitudinal por 
meio de estudo etnográfico visando aprofundar as questões desta pesquisa; (b) utilizar o mesmo arcabouço teórico deste trabalho; porém, investigar outro campo de pesquisa (Uma sugestão é desenvolver a pesquisa em entidades públicas ou empresas mistas. Acredita-se ser relevante investigar a lógica das redes de governança desse tipo de organização, bem como a questão estratégica relacionadas aos atores humanos e não humanos); (c) aprofundar o escopo da relação entre atores humanos e não humanos, na perspectiva do empreendedorismo e da sustentabilidade interna e externa; (d) observar se há diferenças regionais e de porte organizacional nos processos investigados por este trabalho.

\section{Referências}

Alcadipani, R., \& Tureta, C. (2009). Teoria ator-rede e estudos críticos em administração: possibilidades de um diálogo. Cadernos EBAPE.BR, 7(3), 406-418. Recuperado de http://www.scielo.br/pdf/cebape/v7n3/a03v7n3.pdf. doi: 10.1590/S1679-39512009000300003

Andrade, J. A. (2003, setembro). Actor-network theory: uma tradução para compreender o relacional e o estrutural nas redes interorganizacionais? Anais do Encontro Nacional da Associação Nacional de Pós-Graduação e Pesquisa em Administração, Atibaia, SP, Brasil, 27.

Barroso, J. (1996). O estudo da autonomia da escola: da autonomia decretada à autonomia construída. In J. Barroso (Org.), O estudo da escola (pp. 167-189). Portugal: Porto Editora.

Bulgacov, S., Souza, Q. R., Prohmann, J. I. P. de, Coser, C., \& Baraniuk, J. (2007). Administração estratégica: teoria e prática (Col. P. J. Pires). São Paulo: Atlas.

Cavalcanti, M. F. R., \& Alcadipani, R. (2013). Organizações como processos e Teoria Ator-Rede: a contribuição de John Law para os estudos organizacionais. Cadernos EBAPE.BR, 11(4), 556-568. Recuperado de http://www.scielo.br/pdf/cebape/v11n4/06.pdf. doi: 10.1590/S167939512013000400006

Connolly, M., \& James, C. (2011). Reflections on developments in school governance: international perspectives on school governing under pressure. Educational Management Administration \& Leadership, 39(4), 501-509. doi: 10.1177/1741143211406560.

Cronqvist, L. (2007). Tosmana - Tool for small-N analysis (Version 1.3) [Software]. Marburg, Hesse, Alemanha. Retrieved from http://www.tosmana.net

Czarniawska, B. (1998). A narrative approach to organization studies. Thousand Oaks, CA: Sage Publications.

De Meur, G., \& Rihoux, B. (2002). L'analyse quali-quantitative comparée (AQQC-QCA): approche, techniques et applications en sciences humaines. Louvain-la-Neuve, Belgium: AcademiaBruylant.

Denis, J.-L., Langley, A., \& Rouleau, L. (2007). Strategizing in pluralistic contexts: rethinking theoretical frames. Human Relations, 60(1), 179-215. doi: 10.1177/0018726707075288

Fiss, P. C. (2007). A set-theoretic approach to organizational configurations. Academy of Management Review, 32(4), 1180-1198.

Godoy, A. S. (2006). Estudo de caso qualitativo. In C. Godoi, R. Mello, \& A. Silva (Orgs.), Pesquisa qualitativa em estudos organizacionais: paradigmas, estratégias e métodos (pp. 115-146). São Paulo: Saraiva.

Golsorkhi, D., Rouleau, L., Seidl, D., \& Vaara, E. (Eds.). (2010). Cambridge handbook of strategy as practice. Cambridge: Cambridge University Press. 
Jarzabkowski, P. (2004). Strategy as practice: recursiveness, adaptation, and practices-in-use. Organization Studies, 25(4), 529-560. doi: 10.1177/0170840604040675

Jarzabkowski, P. (2005). Strategy as practice: an activity-based approach. California: Sage.

Johnson, G., Langley, A., Melin, L., \& Whittington, R. (2007). Strategy as practice: research directions and resources. New York: Cambridge University Press.

Kalof, L., Dan, A., \& Dietz, T. (2008). Essentials of social research. New York: McGraw Hill Open University Press.

Kjaer, A. M. (2004). Governance (Key Concepts). Cambridge, UK; Malden, MA: Polity Press.

Laderrière, P. (1996). A investigação sobre a escola: perspectiva comparada. In J. Barroso (Org.), $O$ estudo da escola (pp. 41-60). Portugal: Porto Editora.

Latour, B. (1994a). On technical mediation - philosophy, sociology, genealogy. Common Knowledge, $3(2), 29-64$.

Latour, B. (1994b). Pragmatogonies: a mythical account of how humans and nonhumans swap properties. American Behavioral Scientist, 37(6), 791-808. doi: 10.1177/0002764294037006006

Latour, B. (1996). On interobjectivity. Mind, Culture and Activity, 3(4), 228-245. doi: 10.1207/s15327884mca0304_2

Latour, B. (2000). Ciência em ação: como seguir cientistas e engenheiros sociedade afora. São Paulo: Editora UNESP.

Latour, B. (2001). A esperança de Pandora: ensaios sobre a realidade dos estudos científicos. Bauru, SP: EDUSC.

Latour, B. (2005). Reassembling the social: an introduction to Actor-Network-Theory. New York: Oxford University Press.

Matitz, Q. R. S. (2009). Aspectos semânticos, formais e funcionais do conceito desempenho em estudos organizacionais e estratégia: um modelo analítico (Tese de doutorado). Universidade Federal do Paraná, Curitiba, PR, Brasil.

Montenegro, L. M. (2009). Construção de sentidos (sensemaking) em práticas de um processo estratégico: um estudo comparativo em duas instituições de ensino superior do estado do Paraná (Dissertação de mestrado). Universidade Federal do Paraná, Curitiba, PR, Brasil.

Neuman, L. W. (1997). Social research methods: qualitative and quantitative approaches. Boston: Allyn \& Bacon.

Paiva, F. G., Jr., Leão, A. L. M. S. de, \& Mello, S. C. B. de (2011). Validade e confiabilidade da pesquisa qualitativa em administração. Revista de Ciências da Administração, 13(31), 190-209. doi: 10.5007/2175-8077.2011v13n31p190

Pereira, M. I., \& Santos, S. A. (2001). Modelos de gestão: uma análise conceitual. São Paulo: Pioneira Thomson Learning.

Ragin, C. C. (2008). Redesigning social inquiry - fuzzy sets and beyond. Chicago: University of Chicago Press.

Rhodes, R. A. W. (1997). Understanding governance: policy networks, governance, reflexivity and accountability. New York: Open University Press. 
Rhodes, R. A. W. (2007). Understanding governance: ten years on. Organization Studies, 28(8), 12431264. doi: $10.1177 / 0170840607076586$

Rhodes, R. A. W. (2011). Thinking on: a career in public administration. Public Administration, 89(1), 196-212. doi: 10.1111/j.1467-9299.2011.01898.x

Rihoux, B., \& Ragin, C. C. (2009). Configurational comparative methods. Thousand Oaks: Sage Publications.

Saunders, M., Lewis, P., \& Thornhill, A. (2000). Research methods for business students. Harlow, England: Pearson Education.

Tureta, C., \& Alcadipani, R. (2009). O objeto objeto na análise organizacional: a teoria ator-rede como método de análise da participação dos não-humanos no processo organizativo. Cadernos EBAPE.BR, 7(1), 50-70. Recuperado de http://www.scielo.br/pdf/cebape/v7n1/v7n1a05. doi: $10.1590 / \mathrm{S} 1679-39512009000100005$

Tureta, C., \& Alcadipani, R. (2011). Entre o observador e o integrante da escola de samba: os nãohumanos e as transformações durante uma pesquisa de campo. Revista de Administração Contemporânea, 15(2), 209-227. Recuperado de http://www.scielo.br/pdf/rac/v15n2/v15n2a04.pdf. doi: 10.1590/S1415-65552011000200004

Tureta, C., \& Araújo, B. F. V. B. (2013). Escolas de samba: trajetória, contradições e contribuições para os estudos organizacionais. Organizações \& Sociedade, 20(64), 111-129. doi: 10.1590/S198492302013000100008

Tureta, C., Tonelli, M. J., \& Alcadipani, R. (2011). O gerente-ciborgue: metáforas do gestor póshumano. Organizações \& Sociedade, 18(58), 467-486. doi: 10.1590/S1984-92302011000300007

Vergara, S. C. (2009). Projetos e relatórios de pesquisa em administração (11a ed.). São Paulo: Atlas.

Whittington, R. (1996). Strategy as practice. Long Range Planning, 29(5), 731-735.

Whittington, R. (2004). Estratégia após o modernismo: recuperando a prática. Revista de Administração de Empresas, 44(4), 44-53.

Whittington, R. (2006). Completing the practice turn in strategy research. Organization Studies, 27(5), 613-634. doi: 10.1177/0170840606064101

Whittington, R. (2007). Strategy as practice and strategy process: family differences and the sociological eye. Organization Studies, 28(10), 1575-1586. doi: 10.1177/0170840607081557

\section{Dados dos Autores}

Ludmilla Meyer Montenegro

Av. Vereador Olímpio Grande, s/n, Centro, 49500-000, Itabaiana, SE, Brasil. E-mail: ludmilla2907@ gmail.com

Sergio Bulgacov

Rua Itapeva, 474, 01332-000, São Paulo, SP, Brasil. E-mail: sergio.bulgacov@fgv.br 